\title{
Mechanisms of Healing in Coiled Intracranial Aneurysms: A Review of the Literature
}

\author{
W. Brinjikji, D.F. Kallmes, and R. Kadirvel
}

or $\equiv$

\begin{abstract}
SUMMARY: Recanalization of intracranial aneurysms following endovascular coiling remains a frustratingly common occurrence. An understanding of the molecular and histopathologic mechanisms of aneurysm healing following coil embolization is essential to improving aneurysm occlusion rates. Histopathologic studies in coiled human and experimental aneurysms suggest that during the first month postcoiling, thrombus formation and active inflammation occur within the aneurysm dome. Several months following embolization, the aneurysm is excluded from the parent vessel by formation of a neointimal layer, which is often thin and discontinuous, across the aneurysm neck. Numerous coil modifications and systemic therapies have been tested in animals and humans in an attempt to improve the aneurysm-healing process; these modifications have met with variable levels of success. In this review, we summarize the histopathologic and molecular biology of aneurysm healing and discuss how these findings have been applied in an attempt to improve angiographic outcomes in patients with intracranial aneurysms.
\end{abstract}

ABBREVIATION: MMP = matrix metalloproteinase

C oil embolization is increasingly used for treatment of intracranial aneurysms. ${ }^{1}$ While coil embolization has been shown to be safe and effective in the occlusion of the aneurysmal sac, recanalization of the treated aneurysm, resulting in retreatment, occurs in approximately $10 \%-20 \%$ of cases. ${ }^{2,3}$ Because of the high recanalization rates following endovascular coiling, much research has been performed to further understand the biologic mechanisms of aneurysm healing following coil embolization. Such research is often difficult to perform and apply because aneurysms developed in preclinical animal models often do not emulate the conditions of the human aneurysm. Human aneurysm samples are often limited, and histologic and genetic studies are difficult to perform. ${ }^{4}$

Developing an understanding of biologic processes that are conducive to aneurysm healing following coil embolization is essential to improving patient outcomes. Endovascular coiling focuses on the structure and geometry of aneurysms rather than their biologic foundation. Greater understanding of biologic mechanisms of aneurysm healing allows investigators to develop new strategies or make modifications to current devices to accelerate healing and decrease recanalization rates. In this review ar-

From the Department of Radiology, Mayo Clinic, Rochester, Minnesota Please address correspondence to Waleed Brinjikji, MD, 200 1st St SW, Rochester, MN 55905; e-mail: brinjikji.waleed@mayo.edu

- Indicates open access to non-subscribers at www.ajnr.org

三 Indicates article with supplemental on-line table.

http://dx.doi.org/10.3174/ajnr.A4175 ticle, we summarize the current state of the literature regarding the biology of aneurysm healing postcoiling and discuss future directions in aneurysm biology research.

\section{Mechanism of Recurrence}

The major limitations of endovascular treatment are, with time, incomplete occlusion and recurrence or recanalization. ${ }^{2,3}$ There is a strong relationship among aneurysm volume, packing attenuation, and recurrence. ${ }^{5-8}$ The rate of complete obliteration with coils is low in large and giant aneurysms treated with coils; the simple fact that aneurysm volume is cubic in relation to the aneurysm diameter yet coil volume is only linear with deposited coil length guarantees progressively lower packing attenuation with increasing aneurysm size. In general, even in tightly packed, small aneurysms, $75 \%$ of the aneurysm sac is filled with thrombus following coil embolization. ${ }^{5-8}$

Aneurysms often recur early after treatment. Raymond and Darsaut $^{9}$ reported that nearly $50 \%$ of subsequent recurrences were present by 6 months after coiling in humans. Various mechanisms underlying late aneurysm recanalization have been proposed, including the following: 1) growth of the aneurysm itself, ${ }^{10,11}$ 2) poor thrombus organization as a result of the biologically inert platinum coil construction, ${ }^{12} 3$ ) instability of fresh, unorganized thrombus and degradation by fibrolysis, 4) continued transmission of blood pulsation affecting the association of the coil-thrombus complex, ${ }^{13} 5$ ) lack of neointima formation across the neck of aneurysm, ${ }^{14}$ and 6) formation of 

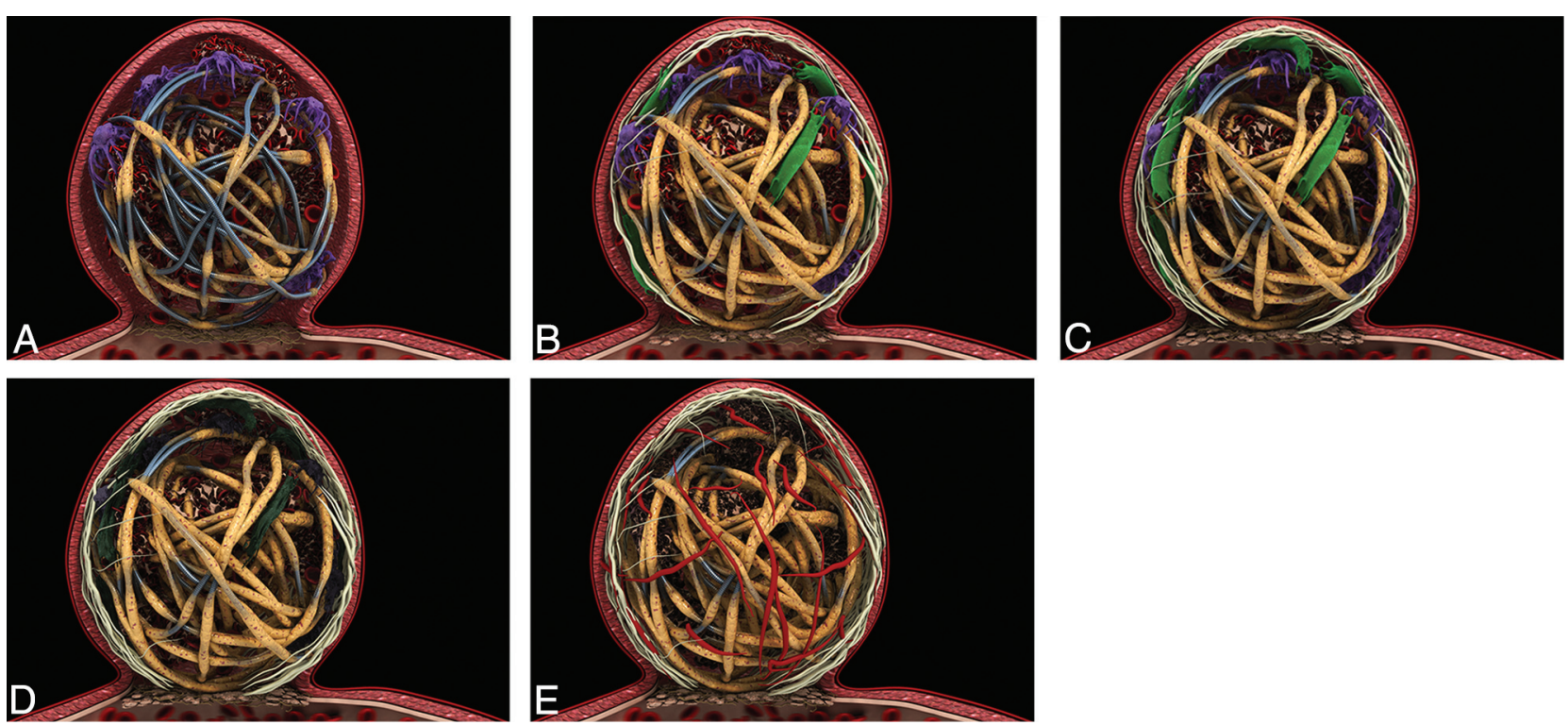

FIG 1. A, Zero-to-7 days: thin fibrin layer covers the coils (tan). Macrophage invasion is seen in the coil periphery (purple). Unorganized thrombus surrounds the coils (red). A thin-but-incomplete fibrin layer is seen at the aneurysm neck. B, One-to-2 weeks: increased fibrin coating of the coils (tan). Macrophages in the coil periphery (purple) and myofibroblast invasion (green) are seen. Note the thin fibrin layer at aneurysm neck. Endothelialization at the neck periphery and along the coil is seen. C, Two weeks to 1 month: increased myofibroblast invasion (green). Thrombus is more organized (red), and macrophages in the aneurysm periphery (purple) are seen. Note increased endothelialization of the aneurysm neck. $D$, One-to-3 months: decreased cellularity occurs within the aneurysm. Myofibroblasts (dark green) and macrophages (dark purple) die through apoptosis. Note increased endothelialization of the aneurysm neck. E, Three months plus: the aneurysm dome is acellular. Vascularized connective tissue is seen in the aneurysm dome (red fibers). Note increased fibrin coverage of coils (tan) and endothelialization of the aneurysm neck. There is a progressive increase in the amount of collagen within the aneurysm through 3 months.

neovessels inside the aneurysms lumen, exposing the aneurysm cavity to blood flow.

\section{Histopathologic Mechanism of Aneurysm Healing following Bare Platinum Coil Embolization}

Histologic Findings of Human Cases. A number of case reports and small case series have demonstrated the histopathologic findings of coiled human aneurysms. ${ }^{4,15-23}$ A summary of histopathology studies in humans is provided in the On-line Table. Histopathologic studies have demonstrated that blood clot composed of red blood cells and fibrin is generally present within the first week of aneurysm coiling. ${ }^{15,17,22-24}$ By the end of the first week following coil embolization, fibroblasts and macrophages begin to invade the clot and foreign body giant cells begin to proliferate about the coils. No endothelialization of the neck occurs within the first week; however, fibrin formation along the coil surface of the aneurysm neck has been reported in some cases (Fig 1A). ${ }^{23}$ One-to-two weeks following coil embolization, coils within the dome begin to be covered with fibrin. Inflammatory cell, macrophage, and fibroblast invasion occurs in most patients. At the site of the aneurysm neck, a thin fibrin membrane forms (Fig 1B). ${ }^{15,17,19,23}$ Some studies have reported that a thin layer of endothelial cells begins to form along the coils of the aneurysm neck during this time. ${ }^{17}$ Two weeks to 1 month following coil embolization, coils in the aneurysm dome are generally covered by a thin layer of fibrin. Fibroblast invasion of the clot in the dome is most vigorous at this phase. In addition, there is continued invasion of the aneurysm dome by inflammatory cells, macrophages, and fibrocytes. Some collagen deposition occurs during this time as well. At the aneurysm neck, there is increased neoin- tima formation with deposition of a thin layer of fibrin along the coil surface of the neck (Fig 1C). ${ }^{15,17,18,21,23}$ Endothelialization at the edges of the neck has been reported. ${ }^{18}$

One-to-three months following embolization, coils remain covered by fibrin. Macrophages have been reported present within the aneurysm sac; however, inflammatory cells are largely absent. Some capillaries are seen in the aneurysm dome as well. ${ }^{15,23}$ At the aneurysm neck, a thin membrane is present, which has been shown to consist of endothelial cells and fibroblasts (Fig $1 D$ ). Three-to-twelve months following embolization, there is increased vascularized connective tissue within the aneurysm dome and about the coils. Continued foreign body reaction with multinucleated giant cells is seen about the aneurysm coils. ${ }^{17,23,25}$ One case report demonstrated that the neck is completely covered by a layer of long slender cells resembling endothelium during this time (Fig $1 E$ ). ${ }^{17}$ After 1 year, the coil is generally incorporated into the aneurysm wall. The aneurysm dome is generally filled with a vascular fibrous connective tissue. There is continued foreign body response with multinucleated giant cells surrounding the coil. Inflammatory cells and macrophages are generally a minor component because there is little inflammatory cellular reaction. The aneurysm neck is generally completely covered with a thin layer of fibrous tissue and endothelial cells. In general, endothelial cells are seen encroaching along the coils at the aneurysm neck. , 15,16,20,23-26 $^{-10}$

\section{Histologic Findings in Animal Models following Bare Platinum Coil Embolization}

Thrombus Formation, Myofibroblast Invasion, and Extracellular Matrix Deposition. The formation of thrombus is essential to 
providing a provisional matrix to allow recruitment of cells involved in the aneurysm-healing process. ${ }^{4,27,28}$ Complete thrombus organization within the aneurysm cavity is associated with improved healing and neointima formation and is best appreciated in aneurysms with increased packing attenuation and small volumes. ${ }^{29}$ Within the first 2 weeks of coil embolization, stasis induced by the coils results in the formation of unorganized thrombus in the aneurysm dome (Fig $2 A,-B){ }^{27,28}$ The core of the thrombus is typically acellular; however, myofibroblasts can be seen in the periphery of the thrombus. The origin of these myofibroblasts remains unclear because some suggest that myofibroblasts arise from differentiation of macrophages present within the thrombus, while others suggest that they arise from the aneurysm wall. ${ }^{27,28}$ During 4 weeks, there is progressive infiltration of the aneurysm dome by myofibroblasts. Myofibroblast infiltration of the aneurysm dome is important because these cells promote collagen synthesis and deposition and express contractile protein processes essential to most wound healing. However, in the case of the rabbit model of intracranial aneurysms, sparse collagen deposition is seen in the aneurysm dome following myofibroblast infiltration and contraction of the aneurysm sac has yet to be appreciated in experimental models. ${ }^{27}$ At approximately 4 weeks following coil embolization, these myofibroblasts undergo apoptosis and are no longer present in the aneurysm dome. ${ }^{27}$ After 10 weeks, the aneurysm dome is primarily composed of vascularized, loose hypocellular tissue (Fig $2 G,-H$ ).

Apoptosis. At approximately 4 weeks following coil embolization, myofibroblasts begin to undergo apoptosis. ${ }^{27}$ Histologic studies of rabbit aneurysms have demonstrated that there is increased expression of activated cleaved caspases at 4 weeks following coil embolization. ${ }^{27}$ Apoptosis of myofibroblasts in the aneurysm dome has been shown to be mediated by both intrinsic (Bcell lymphoma 2/mitochondrial-mediated) and extrinsic (tumor necrosis factor- $\alpha /$ receptor-mediated) pathways of apoptosis. ${ }^{30}$

In a study of 20 rabbit aneurysms undergoing coil embolization, Kadirvel et $\mathrm{al}^{31}$ found that the apoptotic cells in the aneurysm sac were predominantly myofibroblasts. Apoptosis of cells in the aneurysm dome is thought to occur due to lack of physiologic stimulation from pulsatile flow secondary to the stasis induced by the aneurysm coils. This explanation is further supported by the fact that markers of apoptosis are strongly expressed in the aneurysm dome, but not at the aneurysm neck. Furthermore, studies suggest that low wall shear stress diminishes the ability of the aneurysm wall to function and maintain a healthy endothelium and upregulates expression of matrix metalloproteinases, molecules thought to play a role in aneurysm formation and recanalization. ${ }^{32}$ A study performed by Qi et $\mathrm{al}^{32}$ found that low shear stress promotes both vascular smooth muscle cell migration and apoptosis in the rat aorta.

Neointima Formation and Endothelialization. The biology of the aneurysm neck differs from that of the aneurysm dome. Recruitment of endothelial cells to the site of the aneurysm neck is thought to be essential to ensuring adequate healing of the treated aneurysm. Rabbit models generally demonstrate only a single, partial layer of endothelial cells at the aneurysm neck (Fig 2CF). ${ }^{4,15,17,19,21,23,24}$ Swine models of aneurysm healing demon- strate robust neointima formation with a thick layer of vascular smooth muscle cells and robust deposition of endothelial cells. ${ }^{4,33}$ Endothelial cells are primarily seen growing along the coils at the aneurysm neck; this feature has led some investigators to believe that the endothelial cells arise from the adjacent vessel wall. ${ }^{18,25}$ However, recent studies suggest that endothelial cells found at the aneurysm neck may originate from bone marrow-derived endothelial progenitor cells rather than migration of adjacent endothelial cells. ${ }^{34,35}$ Studies in humans suggest that circulating endothelial progenitor cells are mobilized after endovascular therapy; these findings suggest that vessel injury promotes mobilization of the endothelial progenitor cells to the aneurysm neck. ${ }^{36}$ Promotion of endothelial growth along the aneurysm neck is a potential therapeutic target to improve aneurysm healing.

Similarity and Differences in the Wound-Healing Process. Early studies suggested that the mechanism of aneurysm healing following coil embolization would be similar to the well-studied and well-understood wound-healing process. The wound-healing process is classically thought to comprise 4 phases: hemostasis, inflammation, proliferation, and remodeling. ${ }^{37}$ The inflammatory phase depends on recruitment of inflammatory cells such as neutrophils and macrophages, which deposit new extracellular matrix. ${ }^{38}$ Following resolution of the inflammatory phase, fibroblasts and myofibroblasts begin to enter the wound site during the proliferation phase. ${ }^{39}$ This process also relies on neovascularization of the wound to supply fibroblasts and epithelial cells and promote cell migration. ${ }^{40}$ Following migration of fibroblasts, the fibroblasts begin to proliferate and lay down collagen matrix (primarily type III collagen) in the wound site. Later in the proliferative phase, angiogenesis ceases and fibroblasts begin to differentiate into myofibroblasts. Myofibroblasts bind to the surrounding collagen matrix and then contract the wound through contraction of actin. ${ }^{39}$ This process leads to the maturation phase during which the previously deposited type III collagen is replaced by type I collagen and the wound organizes to restore normal tissue strength and apoptosis of cells that are no longer needed, such as endothelial cells and myofibroblasts, occurs. ${ }^{41,42}$

The process of wound healing differs from that of aneurysm healing following coil embolization. Perhaps the most important difference is that the extensive collagen matrix seen following healing of a wound is not seen following coil embolization. Histologic and gene-expression studies have demonstrated that collagen is not highly expressed in treated aneurysms, both wellhealed and poorly healed. The role of myofibroblasts, however, is likely similar in both healing wounds and coiled aneurysms. Myofibroblasts are thought to promote retraction of the aneurysm wall just as they promote wound retraction. Thus, early apoptosis of myofibroblasts, when the aneurysm is still not fully healed, is of so much interest. Prevention of myofibroblastic apoptosis early in the aneurysm-healing process could allow the aneurysm-healing process to more closely emulate the wound-healing process, resulting in improved occlusion rates.

Molecular Biology of Aneurysm Healing and Recanalization. Prior studies have demonstrated that aneurysm recanalization often occurs early, within 6 months of aneurysm coiling. ${ }^{2,3}$ It is clear that much of the biologic activity associated with aneurysm healing 
occurs early, within 4 weeks of coil embolization, and is fairly complex. A number of studies have examined the histologic and biochemical features of recanalization as well as well-healed and poorly healed aneurysms. Proteomic analysis has demonstrated that densely packed aneurysms are associated with up-regulation of cell-to-cell signaling and cell-adhesion molecules within 2 weeks of coil embolization. ${ }^{43}$ Significant differences in differential gene expression exist in well-healed and poorly healed aneurysms. Kadirvel et al ${ }^{44}$ demonstrated that densely packed and well-healed aneurysms have higher expression of adhesion molecules, proteases, and cytokines compared with loosely packed aneurysms. This study found that loosely packed aneurysms did have high gene expression of types I and III collagen; however, histologic analysis found little collagen deposition in these aneurysms. ${ }^{44}$

Osteopontin, a cell-adhesion molecule, has markedly increased expression in densely packed and well-healed aneurysms. ${ }^{44,45}$ This is important because osteopontin plays a key role in chemotaxis and wound healing and helps promote cell adhesion to the extracellular matrix and cell migration. ${ }^{46}$ Furthermore, this molecule inhibits apoptosis and enhances cell proliferations. Case reports that have demonstrated the presence of bony metaplasia in the postcoiling aneurysm sac further highlight the potential role that osteopontin may play in aneurysm healing. Dai et $\mathrm{al}^{47}$ reported 2 cases of bone formation, 1 in the aneurysmal sac and 1 in the aneurysm neck. Plenk et $\mathrm{al}^{48}$ found cartilage neoformation in 6 of 144 experimental aneurysms (4.2\%) and bone formation in 9 of 144 experimental aneurysms (6.3\%). The source of bone formation is still unknown. Potential sources include mesenchymal stem cells arising from the arterial wall, metaplasia of arterial wall smooth muscle cells into chondrocytes, and osteoblasts. These hypotheses are supported by the fact that osteopontin has been shown to promote differentiation of vascular smooth muscle and mesenchymal stem cells to an osteogenic phenotype. ${ }^{49,50}$ Given the potential role of osteopontin in aneurysmal healing, osteopontin has emerged as a potential therapeutic target.

The role of matrix metalloproteinases in aneurysm healing is currently controversial. Bouzaghrane et $\mathrm{al}^{51}$ found that matrix metalloproteinase-9 (MMP-9) may play a key role in aneurysm recanalization in both murine and canine models. MMP-9 messenger RNA and protein were seen in higher concentrations in recanalized aneurysms compared with well-healed aneurysms. However, in a rabbit model, Kadirvel et $\mathrm{al}^{44}$ found that MMP-9 was more highly expressed in well-healed aneurysms than in poorly healed ones. It is likely that MMP-9 expression has properties that are both conducive and inhibitory to aneurysm healing. On the one hand, MMP-9 may cause recanalization by promoting artery injury and aneurysm growth. However, on the other hand, MMP-9 is essential to many important facets of aneurysm healing. MMP-9 regulates migration of smooth muscle cells from the tunica media to the intima; this regulation helps promote neointima formation along the aneurysm neck, an essential component in aneurysm healing. ${ }^{44,52}$ Many studies by using rabbit, canine, and swine models have found that well-healed aneurysms demonstrate endothelial cell proliferation along the aneurysm neck, and MMP-9 may be essential to this process.

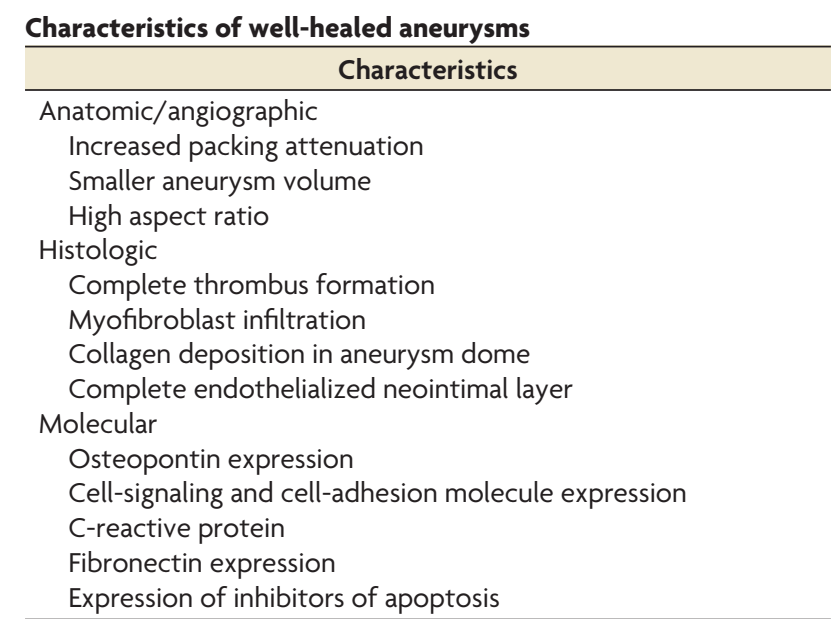

\section{Application of Biologic Findings}

Many investigators have applied the findings from biologic studies to devising means of enhancing the aneurysm-healing process. A summary of the histopathologic and molecular biologic characteristics of well-healed and poorly healed aneurysms is found in the Table. These findings provide the framework for the device modifications and systemic therapies described below.

Modified Coils. Studies highlighting the importance of early thrombus formation in the aneurysm sac led to the development and testing of thrombogenic-/antithrombolytic-coated coils in the experimental rabbit model. However, early studies revealed that both conventional coils and antithrombolytic coils had similar histopathologic and angiographic findings, including a thin membrane of neotintima covering the aneurysm neck and intraaneurysmal scar formation. ${ }^{53}$ Studies highlighting the importance of myofibroblasts in aneurysm healing led to the development of fibroblast-coated coils. Early studies in rabbits found that fibroblast allografts were viable and proliferated in the vascular space in rabbits and remained within the aneurysmal sac. ${ }^{54}$ In a study of rabbits treated with fibroblast-coated coils, Dai et al ${ }^{55,56}$ found that fibroblast-coated coils accelerated early histologic healing and even promoted endothelialization of the aneurysm neck. However, these coils have yet to be tested in humans.

Due to the importance of attenuated packing of the aneurysmal sac in improving long-term occlusion rates, a number of second-generation coils have been developed. The HydroCoil (MicroVention, Tustin, California) was developed with an expandable polymer that allows improved aneurysm filling. ${ }^{57}$ Matrix coils (Stryker, Kalamazoo, Michigan) carry a biodegradable polymer designed to amplify tissue response to the coil and improve aneurysm healing. In a study by using a swine model, Murayama et $\mathrm{al}^{58}$ found that the Matrix coil accelerated aneurysm fibrosis and neointima formation without resultant parent artery stenosis. HydroCoil embolization has been shown to improve aneurysm filling and decrease aneurysm recanalization rates in experimental aneurysms, but without the aggressive cellular response seen with Matrix coils. ${ }^{57}$ In a comparative study of Matrix and hydrogel coils in the rabbit model, Ding et $\mathrm{al}^{59}$ found that HydroCoils resulted in improved long-term occlusion rates compared with Matrix and platinum coils, while Matrix coils had increased inflammation and coil compaction. In a histologic study of 2 human patients treated with Matrix coils, Szikora et 


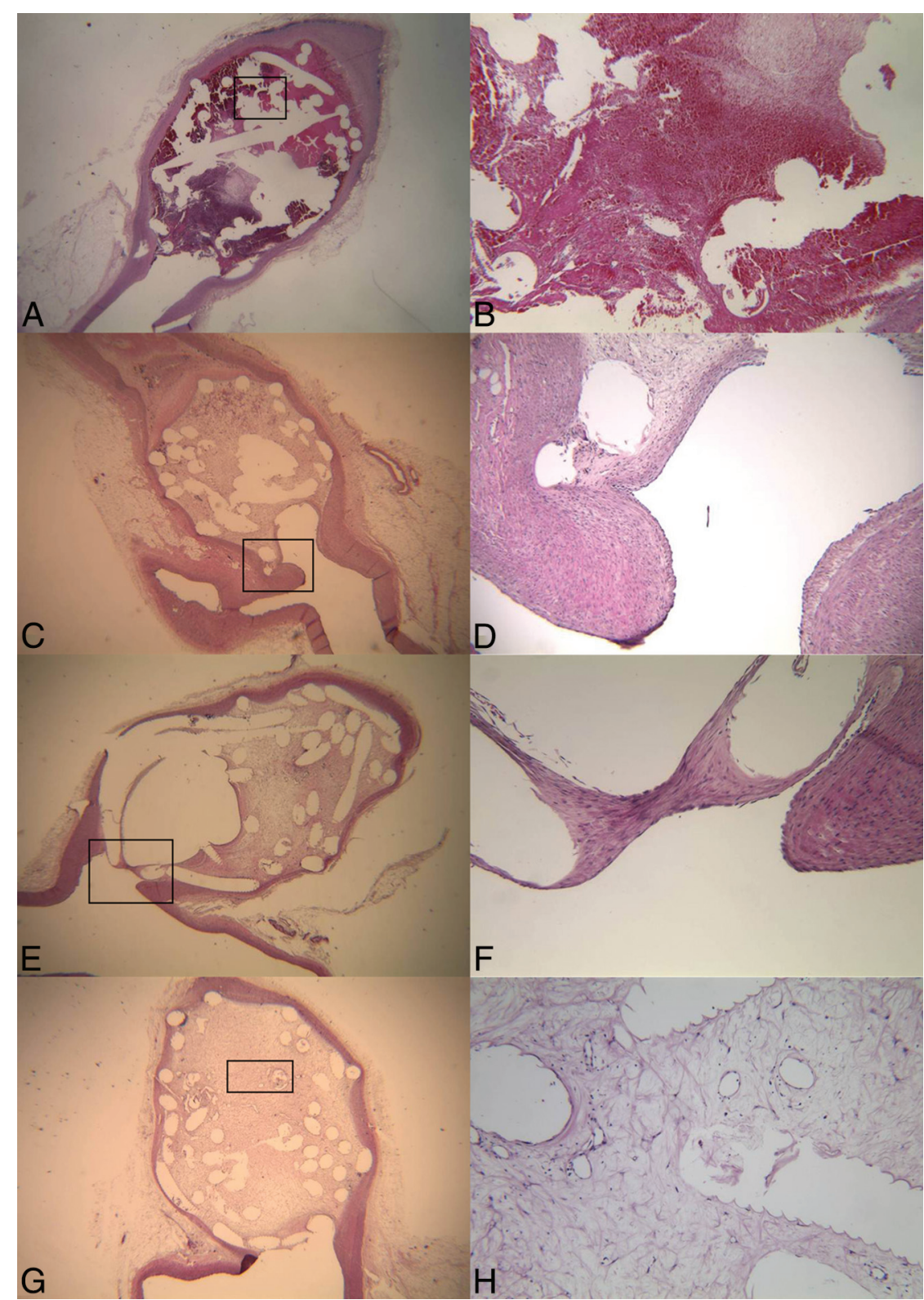

FIG 2. $A$ and $B$, Histopathologic hematoxylin-eosin stains (original magnification $\times 15$ and $\times 60$, respectively) of a rabbit aneurysm dome 1 week postcoiling demonstrate unorganized thrombus filling the aneurysm dome around the coil loops. No endothelialization has occurred at the aneurysm neck. Histopathologic hematoxylin-eosin stains (original magnification $\times 10$ and $\times 150$, respectively) for a rabbit aneurysm dome 6 weeks postcoiling demonstrate loose connective tissue in the aneurysm dome surrounding the coil loops $(C)$ and an incomplete layer of endothelium-lined neointima over the aneurysm neck $(D)$. The neointima and endothelial cells at the neck interface are both continuous with that of the parent artery. $E$ and $F$, Histopathologic hematoxylin-eosin stains (original magnification $\times 10$ and $\times 15$, respectively) 12 months postcoiling demonstrate loose connective tissue in the aneurysm dome surrounding coil loops $(E)$ and a layer of neointima of variable thickness covering the aneurysm neck $(F)$. The neointima and endothelial cells at the neck interface are both continuous with those of the parent artery. $G$ and $H$, Histopathologic hematoxylin-eosin stains (original magnification, $\times 20$ and $\times 125$, respectively) of the aneurysm dome 12 months postcoiling demonstrate loose connective tissue in the aneurysm dome.

$\mathrm{al}^{23}$ found no difference in the histologic appearance of Matrixtreated aneurysms compared with aneurysms treated with bare platinum coils at 1 week. However, at 6 months following coil embolization, the patient treated with Matrix coils had increased neovascularization, smooth muscle cell infiltration, and collagen deposition compared with the patient treated with bare platinum coils. Both HydroCoils and Matrix coils are on the market for use in humans.
Current studies suggest that modified coils are at least equivalent to platinum coils in humans. ${ }^{60,61}$

Systemic Therapies. A number of systemic therapies have been tested to improve aneurysm healing. Because vitamin $C$ is known to stimulate collagen synthesis and cross-linking, it was identified as a potential therapeutic agent for patients with coiling. However, a recent study by using the rabbit aneurysm model found that vitamin $\mathrm{C}$ did not result in improvement of aneurysm occlusion. ${ }^{62}$ Zhang et al ${ }^{63}$ studied the therapeutic benefit of bone marrow-derived endothelial progenitor cell transfusion following aneurysm embolization in a rat model. In this study, bone marrowderived endothelial progenitor cells were labeled and transfused following aneurysm embolization. Zhang et al demonstrated that the labeled cells accumulated at the aneurysm neck, accelerating repair and remodeling of the neck.

Other Therapies. A number of other therapies have been proposed to enhance aneurysm healing following coil embolization. Raymond et $\mathrm{al}^{64}$ tested the efficacy of radiofrequency endothelial embolization following coil embolization in an arterial occlusion dog model and found that coiling with concomitant radiofrequency ablation was more effective in reducing recanalization rates than coiling alone. Cryoablation has also been tested but has not been shown to be as effective as radiofrequency ablation, at least in current animal models. ${ }^{65}$ In situ low-dose radiation has also been tested and has been shown to inhibit recanalization following coil embolization. In a study comparing ${ }^{32} \mathrm{P}$ coated coils with non- ${ }^{32} \mathrm{P}$-coated coils, Raymond et al found that the use of ${ }^{32} \mathrm{P}$ coated coils resulted in improved aneurysm occlusion and more complete neointimal coverage of the aneurysm neck. ${ }^{66,67}$

\section{Future Directions}

As mentioned previously, our understanding of the mechanisms of healing of coiled intracranial aneurysms has led to some practical improvements in coil technology aimed at decreasing the rates of aneurysm recurrence. Our review of the literature suggests that most of the healing process following coiling occurs within the first month postembolization. Future investigations should focus on means to induce and accelerate a healing response similar to that of wound healing with collagen deposition, resulting in in- 
creased occlusion of the aneurysm dome. Coil-modification technologies and systemic administration of medications known to accelerate wound healing are potential means of accomplishing this aim. In addition, therapies and coil modifications aimed at increasing endothelialization of the aneurysm neck to completely exclude the aneurysm from the parent vessel are essential because both rabbit and human models demonstrate that endothelialization along the aneurysm neck is limited. Further research is also needed in improving animal models for embolization of intracranial aneurysms. There is currently no model of aneurysm rupture, growth, or mass effect that would be amenable to coil embolization. There are limited human postmortem examination specimens of postcoiled ruptured intracranial aneurysms.

\section{CONCLUSIONS}

The healing of the postcoiled intracranial aneurysm is a dynamic process. Much of the active healing process occurs within the first 4 weeks of coil embolization. Histopathologic studies have demonstrated that myofibroblasts play an important role in healing of the aneurysm dome, while endothelialization with endothelial progenitor cells is essential for healing the aneurysm neck. Gene and protein studies have demonstrated that factors such as MMPs and osteopontin may play an integral role in the aneurysm-healing process. Findings from histopathologic and molecular studies have been applied to develop treatment methods aimed at improving the aneurysm-healing process.

Disclosures: Waleed Brinjikji-UNRELATED: Grants/Grants Pending: Brain Aneurysm Foundation. * David F. Kallmes—RELATED: Grant: ev3*; UNRELATED: Board Membership: GE Healthcare (Cost Effectiveness Board); Consultancy: ev3, ${ }^{*}$ Comments: preclinical and clinical research; Grants/Grants Pending: ev3, ${ }^{*}$ MicroVention, ${ }^{*}$ Sequent Medical, ${ }^{*}$ Surmodics, ${ }^{*}$ Codman; Royalties: University of Virginia Patent Foundation (Spine Fusion). Ram Kadirvel—RELATED: Grant: National Institutes of Health (NS076491).* *Money paid to the institution.

\section{REFERENCES}

1. Brinjikji W, Lanzino G, Rabinstein AA, et al. Age-related trends in the treatment and outcomes of ruptured cerebral aneurysms: a study of the Nationwide Inpatient Sample 2001-2009. AJNR Am J Neuroradiol 2013;34:1022-27

2. Crobeddu E, Lanzino G, Kallmes DF, et al. Review of 2 decades of aneurysm-recurrence literature. Part 1. Reducing recurrence after endovascular coiling. AJNR Am J Neuroradiol 2013;34:266-70

3. Crobeddu E, Lanzino G, Kallmes DF, et al. Review of 2 decades of aneurysm-recurrence literature. Part 2. Managing recurrence after endovascular coiling. AJNR Am J Neuroradiol 2013;34:481-85

4. Dai D, Ding YH, Danielson MA, et al. Histopathologic and immunohistochemical comparison of human, rabbit, and swine aneurysms embolized with platinum coils. AJNR Am J Neuroradiol 2005;26:2560-68

5. Knap D, Gruszczyńska K, Partyka R, et al. Results of endovascular treatment of aneurysms depending on their size, volume and coil packing density. Neurol Neurochir Pol 2013;47:467-75

6. Leng B, Zheng Y, Ren J, et al. Endovascular treatment of intracranial aneurysms with detachable coils: correlation between aneurysm volume, packing, and angiographic recurrence. J Neurointerv Surg 2014;6:595-99

7. Slob MJ, Sluzewski M, van Rooij WJ. The relation between packing and reopening in coiled intracranial aneurysms: a prospective study. Neuroradiology 2005;47:942-45

8. Sluzewski M, van Rooij WJ, Slob MJ, et al. Relation between aneurysm volume, packing, and compaction in 145 cerebral aneurysms treated with coils. Radiology 2004;231:653-58
9. Raymond J, Darsaut TE. An approach to recurrent aneurysms following endovascular coiling. J Neurointerv Surg 2011;3:314-18

10. Abdihalim M, Watanabe M, Chaudhry SA, et al. Are coil compaction and aneurysmal growth two distinct etiologies leading to recurrence following endovascular treatment of intracranial aneurysm? J Neuroimaging 2014;24:171-75

11. Hasan DM, Nadareyshvili AI, Hoppe AL, et al. Cerebral aneurysm sac growth as the etiology of recurrence after successful coil embolization. Stroke 2012;43:866-68

12. Yuki I, Lee D, Murayama Y, et al. Thrombus organization and healing in an experimental aneurysm model. Part II. The effect of various types of bioactive bioabsorbable polymeric coils. J Neurosurg 2007;107:109-20

13. Boecher-Schwarz HG, Ringel K, Kopacz L, et al. Ex vivo study of the physical effect of coils on pressure and flow dynamics in experimental aneurysms. AJNR Am J Neuroradiol 2000;21:1532-36

14. Ozawa T, Tamatani S, Koike $\mathrm{T}$, et al. Histological evaluation of endothelial reactions after endovascular coil embolization for intracranial aneurysm: clinical and experimental studies and review of the literature. Interv Neuroradiol 2003;9:69-82

15. Bavinzski G, Talazoglu V, Killer M, et al. Gross and microscopic histopathological findings in aneurysms of the human brain treated with Guglielmi detachable coils. J Neurosurg 1999;91:284-93

16. Castro E, Fortea F, Villoria F, et al. Long-term histopathologic findings in two cerebral aneurysms embolized with Guglielmi detachable coils. AJNR Am J Neuroradiol 1999;20:549-52

17. Groden C, Hagel C, Delling G, et al. Histological findings in ruptured aneurysms treated with GDCs: six examples at varying times after treatment. AJNR Am J Neuroradiol 2003;24:579-84

18. Horowitz MB, Purdy PD, Burns D, et al. Scanning electron microscopic findings in a basilar tip aneurysm embolized with Guglielmi detachable coils. AJNR Am J Neuroradiol 1997;18:688-90

19. Ishihara S, Mawad ME, Ogata K, et al. Histopathologic findings in human cerebral aneurysms embolized with platinum coils: report of two cases and review of the literature. AJNR Am J Neuroradiol 2002;23:970-74

20. Molyneux AJ, Ellison DW, Morris J, et al. Histological findings in giant aneurysms treated with Guglielmi detachable coils: report of two cases with autopsy correlation. J Neurosurg 1995:83:129-32

21. Shimizu S, Kurata A, Takano M, et al. Tissue response of a small saccular aneurysm after incomplete occlusion with a Guglielmi detachable coil. AJNR Am J Neuroradiol 1999;20:546-48

22. Stiver SI, Porter PJ, Willinsky RA, et al. Acute human histopathology of an intracranial aneurysm treated using Guglielmi detachable coils: case report and review of the literature. Neurosurgery 1998;43:1203-08

23. Szikora I, Seifert P, Hanzely Z, et al. Histopathologic evaluation of aneurysms treated with Guglielmi detachable coils or Matrix detachable microcoils. AJNR Am J Neuroradiol 2006;27:283-88

24. Nakahara T, Sakamoto S, Hamasaki O, et al. Post-mortem pathological examination of two patients after intraaneurysmal embolization using Guglielmi detachable coils. Interv Neuroradiol 2003; 9(suppl 1):57-62

25. Suda Y, Kikuchi K, Shioya H, et al. Long-term histopathology of intracranial aneurysms after endovascular treatment with coil: report of two cases with ultrastructural evaluations by scanning electron microscopy. Interv Neuroradiol 1999;5(suppl 1):225-31

26. Mizoi K, Yoshimoto T, Takahashi A, et al. A pitfall in the surgery of a recurrent aneurysm after coil embolization and its histological observation: technical case report. Neurosurgery 1996;39:165-68; discussion 168-69

27. Dai D, Ding YH, Kadirvel R, et al. A longitudinal immunohistochemical study of the healing of experimental aneurysms after embolization with platinum coils. AJNR Am J Neuroradiol 2006;27: 736-41

28. Kallmes DF, Helm GA, Hudson SB, et al. Histologic evaluation of platinum coil embolization in an aneurysm model in rabbits. Radiology 1999;213:217-22 
29. Ding YH, Dai D, Kadirvel R, et al. Relationship between aneurysm volume and histologic healing after coil embolization in elastaseinduced aneurysms: a retrospective study. AJNR Am J Neuroradiol 2008;29:98-101

30. Kadirvel R, Ding YH, Dai D, et al. Molecular indices of apoptosis activation in elastase-induced aneurysms after embolization with platinum coils. Stroke 2007;38:2787-94

31. Kadirvel R, Ding YH, Dai D, et al. Intrinsic pathway-mediated apoptosis in elastase-induced aneurysms in rabbits. AJNR Am J Neuroradiol 2010;31:165-69

32. Qi YX, Qu MJ, Long DK, et al. Rho-GDP dissociation inhibitor alpha downregulated by low shear stress promotes vascular smooth muscle cell migration and apoptosis: a proteomic analysis. Cardiovasc Res 2008;80:114-22

33. Mitome-Mishima Y, Yamamoto M, Yatomi K, et al. Endothelial cell proliferation in swine experimental aneurysm after coil embolization. PLoS One 2014;9:e89047

34. Fang $\mathrm{X}$, Zhao R, Wang $\mathrm{K}$, et al. Bone marrow-derived endothelial progenitor cells are involved in aneurysm repair in rabbits. J Clin Neurosci 2012;19:1283-86

35. Li ZF, Fang XG, Yang PF, et al. Endothelial progenitor cells contribute to neointima formation in rabbit elastase-induced aneurysm after flow diverter treatment. CNS Neurosci Ther 2013;19:352-57

36. Wei HJ, Wang D, Chen JL, et al. Mobilization of circulating endothelial progenitor cells after endovascular therapy for ruptured cerebral aneurysms. Neurosci Lett 2011;498:114-18

37. Yamaguchi Y, Yoshikawa K. Cutaneous wound healing: an update. J Dermatol 2001;28:521-34

38. Martin P, Leibovich SJ. Inflammatory cells during wound repair: the good, the bad and the ugly. Trends Cell Biol 2005;15:599-607

39. Hinz B. Masters and servants of the force: the role of matrix adhesions in myofibroblast force perception and transmission. Eur JCell Biol 2006;85:175-81

40. Wong VW, Crawford JD. Vasculogenic cytokines in wound healing. Biomed Res Int 2013;2013:190486

41. Greenhalgh DG. The role of apoptosis in wound healing. Int J Biochem Cell Biol 1998;30:1019-30

42. Stadelmann WK, Digenis AG, Tobin GR. Physiology and healing dynamics of chronic cutaneous wounds. Am J Surg 1998;176: 26S-38S

43. Kadirvel R, Ding YH, Dai D, et al. Proteomic analysis of aneurysm healing mechanism after coil embolization: comparison of dense packing with loose packing. AJNR Am J Neuroradiol 2012;33: 1177-81

44. Kadirvel R, Ding YH, Dai D, et al. Differential gene expression in well-healed and poorly healed experimental aneurysms after coil treatment. Radiology 2010;257:418-26

45. Kadirvel R, Ding YH, Dai D, et al. Differential expression of genes in elastase-induced saccular aneurysms with high and low aspect ratios. Neurosurgery 2010;66:578 -84; discussion 584

46. Giachelli CM, Liaw L, Murry CE, et al. Osteopontin expression in cardiovascular diseases. Ann N Y Acad Sci 1995;760:109-26

47. Dai D, Ding YH, Kadirvel R, et al. Bone formation in elastase-induced rabbit aneurysms embolized with platinum coils: report of 2 cases. AJNR Am J Neuroradiol 2007;28:1176-78

48. Plenk H Jr, Shum JC, Cruise GM, et al. Cartilage and bone neoformation in rabbit carotid bifurcation aneurysms after endovascular coil embolization. Eur Cell Mater 2008;16:69-79

49. Chen Q, Shou P, Zhang L, et al. An osteopontin-integrin interaction plays a critical role in directing adipogenesis and osteogenesis by mesenchymal stem cells. Stem Cells 2014;32:327-37

50. Montezano AC, Zimmerman D, Yusuf H, et al. Vascular smooth muscle cell differentiation to an osteogenic phenotype involves TRPM7 modulation by magnesium. Hypertension 2010;56:453-62

51. Bouzeghrane F, Darsaut T, Salazkin I, et al. Matrix metalloproteinase- 9 may play a role in recanalization and recurrence after therapeutic embolization of aneurysms or arteries. J Vasc Interv Radiol 2007;18:1271-79

52. Johnson JL, Dwivedi A, Somerville M, et al. Matrix metalloproteinase (MMP)-3 activates MMP-9 mediated vascular smooth muscle cell migration and neointima formation in mice. Arterioscler Thromb Vasc Biol 2011;31:e35-44

53. Bavinzski G, Richling B, Binder BR, et al. Histopathological findings in experimental aneurysms embolized with conventional and thrombogenic/antithrombolytic Guglielmi coils. Minim Invasive Neurosurg 1999;42:167-74

54. Marx WE, Cloft HJ, Helm GA, et al. Endovascular treatment of experimental aneurysms by use of biologically modified embolic devices: coil-mediated intraaneurysmal delivery of fibroblast tissue allografts. AJNR Am J Neuroradiol 2001;22:323-33

55. Dai D, Ding YH, Danielson MA, et al. Endovascular treatment of experimental aneurysms with use of fibroblast transfected with replication-deficient adenovirus containing bone morphogenetic protein-13 gene. AJNR Am J Neuroradiol 2008;29:739-44

56. Dai D, Ding YH, Danielson MA, et al. Endovascular treatment of experimental aneurysms by use of fibroblast-coated platinum coils: an angiographic and histopathologic study. Stroke 2007;38:170-76

57. Kallmes DF, Fujiwara NH. New expandable hydrogel-platinum coil hybrid device for aneurysm embolization. AJNR Am J Neuroradiol 2002;23:1580-88

58. Murayama Y, Tateshima S, Gonzalez NR, et al. Matrix and bioabsorbable polymeric coils accelerate healing of intracranial aneurysms: long-term experimental study. Stroke 2003;34:2031-37

59. Ding YH, Dai D, Lewis DA, et al. Angiographic and histologic analysis of experimental aneurysms embolized with platinum coils, Matrix, and HydroCoil. AJNR Am J Neuroradiol 2005;26:1757-63

60. McDougall CG, Johnston SC, Gholkar A, et al. Bioactive versus bare platinum coils in the treatment of intracranial aneurysms: the MAPS (Matrix and Platinum Science) trial. AJNR Am J Neuroradiol 2014;35:935-42

61. White PM, Lewis SC, Gholkar A, et al. Hydrogel-coated coils versus bare platinum coils for the endovascular treatment of intracranial aneurysms (HELPS): a randomised controlled trial. Lancet 2011; 377:1655-62

62. Dai D, Yong-Hong D, Rezek I, et al. Healing of saccular aneurysms following platinum coil embolization: lack of improved efficacy with vitamin C supplementation. J Neurointerv Surg 2013;5:591-96

63. Zhang S, An Q, Li Q, et al. Therapeutic benefit of bone marrowderived endothelial progenitor cell transplantation after experimental aneurysm embolization with coil in rats. PLoS One 2014; 9:e90069

64. Raymond J, Savard P, Salazkin I, et al. Radiofrequency endothelial ablation prevents recanalization after endovascular coil occlusion: in vitro and in vivo assessment. J Vasc Interv Radiol 2010;21:101-07

65. Raymond J, Metcalfe A, Salazkin I, et al. Endoluminal cryotherapy to prevent recanalization after endovascular occlusion with platinum coils. J Vasc Interv Radiol 2006;17:1499-504

66. Raymond J, Leblanc P, Desfaits AC, et al. In situ beta radiation to prevent recanalization after coil embolization of cerebral aneurysms. Stroke 2002;33:421-27

67. Raymond J, Mounayer C, Salazkin I, et al. Safety and effectiveness of radioactive coil embolization of aneurysms: effects of radiation on recanalization, clot organization, neointima formation, and surrounding nerves in experimental models. Stroke 2006;37:2147-52 